\title{
Business Student And Practitioner Work Goals And Their Implications
}

Clinton H. Richards, University of Nevada, Las Vegas William J. Corney, University of Nevada, Las Vegas

\begin{abstract}
The correspondence between individual work goals and available organizational rewards is a primary determinant of job satisfaction and motivation and is also likely to impact job performance. Differences between upper and lower division business students' work goals suggest that changes had occurred as the students progressed through the curriculum that are likely to be functional for their work adjustment in modern organizations affected by current trends in job and organization design. However, some student priorities remained poorly matched with the available rewards and work requirements they are likely to find in these organizations. The mismatched priorities contrasted sharply with those displayed by U.S. managers in a previous study.
\end{abstract}

Keywords: work goals, work adjustment, reward preferences, job satisfaction

\section{INTRODUCTION}

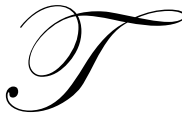

he concept of person-job (P-J) fit is ubiquitous in organizational behavior (OB) and industrial/organizational (I/O) psychology" (Edwards, 1991, p. 283). The fit between work competencies and requirements and between reward preferences and their availability are considered critical for satisfaction, motivation, and performance (Dawis and Lofquist, 1984; Hershenson, 1996). Business educators have naturally focused on the matching of student work competencies with work requirements, but the fit between reward preferences and reward availability has the greater impact on satisfaction and motivation (Locke, 1976; Robertson, 1990; Edwards, 1991; Maier and Brunstein, 2001).

The landmark Meaning of Work project (MOW International Research Team, 1987) identified employee reward preferences by examining their work goals. The project examined and compared the work goals and attitudes of managers, first-line supervisors, and non-supervisory employees in seven industrialized countries. Perhaps the "most empirically rigorous research ever undertaken to understand the meanings people attach to their work roles" (Brief, 1991, p. 176), the importance and structure of its core concepts continue to be supported by current research (Harpaz and Fu, 2002; Peterson and Ruiz-Quintanilla, 2003) and used in cross-cultural studies (e.g., see Pearson and Chatterjee, 1999; Chan and Pearson, 2002; Corney and Richards, 2001, 2005; Ardichvili, 2005). The MOW research team chose the 11 work goals shown in Table 1 after an extensive international review of studies on work values and job satisfaction. The list includes learning and expressive work goals related to intrinsic rewards as well as work goals requiring extrinsic rewards for their satisfaction. A number of the work goals are impacted by current job and organization design trends. Some work goal priorities are highly compatible with them while others are not. The expected result is differing levels of satisfaction and motivation. Some of the work goals are also likely to affect the development of work competencies. That combined with enhanced motivation should positively affect the performance of individuals who place a high priority on such work goals. 


\title{
Table 1: MOW Work Goals
}

\author{
A - A lot of opportunity to learn new things \\ B - Good interpersonal relations \\ C - Good opportunity for upgrading or promotion \\ D - Convenient work hours \\ E - A lot of variety \\ F - Interesting work (work that you really like) \\ G - Good job security \\ $\mathrm{H}$ - A good match between job requirements and your abilities and experience \\ I - Good pay \\ J - Good physical working conditions (such as light, temperature, cleanliness, low noise level) \\ $\mathrm{K}$ - A lot of autonomy (You decide how you do your work)
}

The current study examines the work goal priorities of upper and lower-division business students and discusses their compatibility with the rewards and work requirements likely to be found in modern organizations affected by current job and organization design trends. Student priorities are also compared to those of U.S. employees surveyed in a previous study (Harpaz, 1990). We conclude with a discussion of implications for student work adjustment and for managers, educators, and researchers. We begin with a brief review of work adjustment concepts and theory followed by a description of current job and organization design trends affecting work adjustment.

\section{WORK ADJUSTMENT PROCESSES AND EFFECTS}

Work adjustment is the "continuous and dynamic process by which the individual seeks to achieve and maintain correspondence with the work environment' (Dawis and Lofquist, 1984, p. 55) by changing it or adjusting to it by changing reward preferences or competencies (Dawis and Lofquist, 1984). Education and socialization are two key factors in addition to direct experience that can affect reward preferences and competencies (Dawis and Lofquist, 1984; Hershenson, 1996, Peterson and Ruiz-Quintanilla, 2003). The correspondence between work competencies and requirements has its primary effect on performance while the correspondence between work goals and available rewards has its primary effect on job satisfaction and motivation. However, both competencies and work goals can have secondary effects on satisfaction and performance due to interactions between work competencies and work goals and between performance and satisfaction (Hershenson, 1996). Research supports the contention that satisfaction of intrinsic work goals can increase performance (Dodd and Ganster, 1996; Dunegan et al., 2002; Leach et al., 2003). Competencies, in turn, can impact not only performance but also reward availability and resulting satisfaction.

\section{Work Goal Importance}

The importance of a goal affects its impact on job satisfaction (Harris et al., 2003) and depends on the intrinsic value of its satisfaction as well as its instrumentality in attaining other valued rewards and outcomes. Some goals may be very instrumental in obtaining valued rewards and outcomes but have little intrinsic value while other may provide significant intrinsic and instrumental value. Variety, autonomy, and learning opportunities are three of the MOW work goals likely to be intrinsically rewarding and also instrumental in enhancing competencies and obtaining performance-based rewards. The goal of matching job requirements with abilities, if accomplished, should also result in more intrinsically rewarding work as well as higher performance and more performance-based rewards. Good interpersonal relations can also be satisfying in themselves and instrumental in accomplishing task goals.

The perceived importance of a work goal can also be affected positively or negatively by the probability of attaining the goal (Aronson, 1995; Welsch, 2005). Functional work goal adjustment occurs when individuals are able to reduce their emphasis on work goals that are unattainable and increase attention to work goals that are attainable and have high intrinsic and instrumental value. Dissatisfaction results when the individual is unable to adjust work goal importance to lowered availability. 
The relatively high levels of satisfaction found among U.S. employees (Clark, 2005) suggest that they have generally been successful in adjusting to the availability of rewards in modern organizational environments. However, some work goals attached to important needs like security may continue to be emphasized even when they are unlikely to be satisfied. Employees may also place more or less than appropriate emphasis on a work goal because they misjudge its attainability, its instrumentality, or its intrinsic value. Information and knowledge are the keys to avoiding these mistakes and can come through experiential or vicarious learning. Modeling and imitation are important forms of the latter (Bandura, 1977) that Hershenson (1996) contends are particularly influential in shaping work goals. Lower satisfaction, and in some cases lower performance, are expected when employees inaccurately assess the importance of work goals.

\section{JOB DESIGN AND ORGANIZATIONAL TRENDS AFFECTING WORK ADJUSTMENT}

Three approaches to job design that have shown considerable success in the past and continue to influence are the job characteristic model (Hackman and Oldham, 1980), socio-technical systems theory (Trist, 1981) and reengineering (Hammer and Champy, 1993). Although the focus of the three models varies from individual jobs (job characteristics model) to work groups (socio-technical theory) to organization-spanning processes (reengineering), all share certain principles and consequences. They all call for increased autonomy and greater task variety, which is likely to not only make the job more interesting but also heighten the need for employee learning in order to match competencies with the increased job requirements. Two of the three models share team-based principles critical to effective use of the part-time, temporary and full-time teams that are becoming increasingly pervasive in today's organizations (Stewart et al., 1999). Structurally, all of the approaches reduce the need for supervision and therefore facilitate the move to flatter organizational hierarchies. While obvious cost advantages can ensue, a negative consequence for managers is the resulting reduction in promotion opportunities.

Modern organizations are also characterized by reduced job security. Downsizing and outsourcing trends play a major role in this. However, employee attitudes have also contributed to a change in the social contract between employee and employer from reciprocal loyalty to rewards based on today rather than yesterday's contributions (Carroll and Bucholtz, 2006).

A number of the MOW work goals are affected by these changes in job and organization design. Employees with strong variety, autonomy, and learning work goals should experience greater satisfaction and motivation in work settings shaped by current job design approaches, perform better in these settings, and develop competencies to better match future assignments. Recognition of the importance of matching abilities with expanded job requirements will also serve employees well in modern organizations. Those in increasingly common team-oriented work environments are also likely to find good interpersonal relations instrumental in task accomplishment. On the other hand, strong promotion and job security goals do not appear conducive to job satisfaction given current downsizing and outsourcing trends and the flattening of organizational structures.

\section{STUDENT WORK GOALS}

Four hundred and ten students taking business courses at an urban university in the southwestern U.S. were asked to rate the importance of the MOW work goals (see Table 1) on a ten point scale. Students were also asked to provide information on age, gender, and year in college. Ages ranged from 17 to 55, with a mean of 23 years and 77 percent between 18 and 24. Fifty percent were female. Thirty-seven percent identified themselves as freshmen or sophomores and 58 percent identified themselves as juniors or seniors. Five percent did not report their class standing.

\section{Hypotheses}

Previous research on the reasons students select a business major suggests good pay, promotion opportunities, and interesting work will be top-rated goals among lower division students (Kim et al., 2002). However, the perceived importance of two of these work goals is expected to change significantly as students progress through the business curriculum. The perceived importance of interesting work is expected to increase 
while the perceived importance of promotion opportunities is expected to decrease. The greatest change, however, is expected to be in the perceived importance of learning opportunities. An emphasis on the importance of learning throughout the business curriculum is expected to lead upper division students to rate the importance of learning opportunities much more highly than lower division students. Smaller but still significant adjustments in other work goal priorities are proposed to result from exposure to information in the business curriculum about job design and organizational trends that 1) positively affect learning, expressive, and interpersonal work goals and 2) negatively affect security and promotion opportunities. The introduction to business and principles of management courses typically provide limited coverage of these trends, and both courses are part of the core curriculum of the business students participating in this study.

\section{Results}

Table 2 displays the work goal priorities of upper and lower division students in the current study and managers, first-line supervisors, and non-supervisory employees in the Harpaz study (1990). The order of work goals listed in the first column reflects the managers' ranking of the work goals, which are shown in column two. The third and fourth columns display the rankings of the first-line supervisors and the non-supervisory employees. Upper and lower division student ranks and means computed from ANOVA models are shown in the next four columns. Significant differences between the two student groups are shown in column nine. The final column displays a size-of-effect measure that was calculated by dividing the differences between the upper and lower division students' adjusted work goal means by the pooled standard deviations. Others have used similar analyses in evaluating the practical significance of training effects (e.g., Schalaefli et al., 1985; Rest, 1986, 1994; and Abdolmohammadi and Reeves, 2000) by dividing differences in pre-treatment and post-treatment scores by standard deviations. Cohen (1969) suggests practical significance cut points of .20 (small but meaningful effects), .50 (medium effects) and .80 (large effects).

Table 2: Employee and Student Work Goals

\begin{tabular}{|c|c|c|c|c|c|c|c|c|c|}
\hline \multirow[b]{3}{*}{ Work Goals } & \multicolumn{3}{|c|}{ Employees $^{1}$} & \multicolumn{4}{|c|}{ Students ${ }^{2 .}$} & & \\
\hline & \multirow{2}{*}{$\begin{array}{c}\text { Mgr } \\
\text { Rank }\end{array}$} & \multirow{2}{*}{$\begin{array}{c}\begin{array}{c}\text { Super- } \\
\text { visor }\end{array} \\
\text { Rank }\end{array}$} & \multirow{2}{*}{$\begin{array}{c}\text { Non } \\
\text { Super }\end{array}$} & \multicolumn{2}{|c|}{$\begin{array}{c}\text { Upper } \\
\text { Division }\end{array}$} & \multicolumn{2}{|c|}{$\begin{array}{l}\text { Lower } \\
\text { Division }\end{array}$} & \multicolumn{2}{|c|}{$\begin{array}{c}\text { Student } \\
\text { Differences }\end{array}$} \\
\hline & & & & Rank & Mean & Rank & Mean & $\begin{array}{c}\text { Sign. } \\
\text { Level }^{3}\end{array}$ & $\begin{array}{l}\text { Effect } \\
\text { Size }^{4}\end{array}$ \\
\hline Interesting Work & 1 & 1 & 1 & 1 & 9.47 & 2 & 9.15 & .01 & .27 \\
\hline High Autonomy & 2 & 5 & 9 & 11 & 8.25 & 10 & 7.99 & .10 & .16 \\
\hline High Variety & 3 & 6 & 7 & 9 & 8.32 & 11 & 7.94 & .05 & .22 \\
\hline $\begin{array}{l}\text { Match Abilities } \\
\text { with Job }\end{array}$ & 4 & 8 & 5 & 10 & 8.26 & 9 & 8.17 & 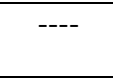 & .06 \\
\hline $\begin{array}{c}\text { Learning } \\
\text { Opportunities } \\
\end{array}$ & 5 & 3 & 4 & 5 & 8.84 & 8 & 8.38 & .01 & .31 \\
\hline Good Pay & 6 & 2 & 3 & 3 & 9.19 & 3 & 9.08 & ---- & .08 \\
\hline $\begin{array}{c}\text { Good } \\
\text { Interpersonal } \\
\text { Relations } \\
\end{array}$ & 7 & 7 & 6 & 4 & 8.92 & 5 & 8.62 & .05 & .21 \\
\hline $\begin{array}{l}\text { Good Job } \\
\text { Security } \\
\end{array}$ & 8 & 4 & 3 & 6 & 8.82 & 4 & 8.97 & ---- & .11 \\
\hline $\begin{array}{l}\text { Convenient } \\
\text { Work Hours } \\
\end{array}$ & 9 & 10 & 8 & 7 & 8.49 & 7 & 8.51 & $\begin{array}{l}--- \\
-1\end{array}$ & .01 \\
\hline $\begin{array}{c}\text { Promotion } \\
\text { Opportunities } \\
\end{array}$ & 10 & 9 & 10 & 2 & 9.34 & 1 & 9.23 & ---- & .10 \\
\hline $\begin{array}{l}\text { Good Working } \\
\text { Conditions }\end{array}$ & 11 & 11 & 11 & 8 & 8.49 & 6 & 8.52 & ---- & .02 \\
\hline
\end{tabular}


A number of the results shown in Table 2 were expected. The top rankings of interesting work, promotion opportunities, and good pay among lower-division business students are consistent with previously cited research on choice of a business major. The significant differences that were found between lower and upper division student work goals were also hypothesized. The largest and most statistically significant difference was in the perceived importance of learning opportunities. Differences in the perceived importance of interesting work, good interpersonal relations, and high variety were also significant at the .05 level or beyond. Similar levels of significance were obtained when ANOVA models were used that treated year in school as a four-level covariate rather than a two-level factor. The results of size-of-effect analyses shown in Table 2 suggest that the statistically significant results correspond with small but meaningful effects. Contrary to expectations, however, there was no decrease in the perceived importance of promotional opportunities and no significant decrease in the importance of job security from lower to upper division students. Moreover, there was no significant increase in the perceived importance of matching job abilities with job requirements and the increase in the perceived importance of autonomy was significant at the .10 level only. Upper as well as lower division students gave low ratings to both of these work goals.

Employee rankings in the Harpaz study reveal a quite different set of priorities that suggest better work adjustment to today's organizational realities. Employees gave much lower priority to promotion opportunities and higher priority to autonomy, variety, and the matching of abilities with job requirements.

\section{IMPLICATIONS AND CONCLUSIONS}

University students will find themselves entering a dynamic workplace characterized by global competitiveness and diminished opportunities for life-time jobs. It appears that some of the student attitudes toward workplace goals found in this study are compatible with this reality while others are not.

\section{Incompatible Work Goal Priorities}

The low rating both upper and lower division students gave to the importance of matching abilities to job requirements is very troubling since a good match is likely to result in more intrinsically rewarding work, higher performance, and greater performance-based extrinsic rewards. This is particularly true in today's organizations as job requirements change and increase. The low importance students attributed to high variety and autonomy is equally troubling. These attributes are prominent in popular job design theory and can be instrumental in increasing competencies and performance as well as in attaining greater intrinsic and extrinsic rewards. Although upper division students did give more weight to these work goals than their lower-division counterparts, both groups rated them low. Employees in the Harpaz study, in contrast, did not appear to underestimate the importance of these job attributes. Non-supervisory, supervisory, and managerial personnel all placed greater importance on variety and autonomy than did students. Furthermore, differences in the employee rankings appear to be consistent with likely differences in the attainability and perhaps value of these work goals at different hierarchical levels. Managers ranked autonomy and variety highest (at $2^{\text {nd }}$ and $3^{\text {rd }}$ ) among the three employee groups while non-supervisory personnel ranked them lowest. These differences appear functional for work adjustment since the attributes are likely to become more available at higher organizational levels and may be more instrumental in preparing for future work requirements at higher levels also.

The high rating both upper and lower division students gave to the importance of promotion opportunities is also cause for concern given the trend toward downsizing and the flattening of organization structures. Employees, on the other hand, appear to have adjusted to these trends since all levels ranked the work goal among the bottom three. Upper division students' views on job security in the current workplace were more realistic than non-supervisory employees and first-level supervisors but less realistic than those of higher level managers who appear to have adjusted to the reality of lower job security in modern organizations. A greater sense of competency may also make these managers less sensitive to job security concerns than other employees. 


\section{Educational Implications}

Students should benefit from a greater emphasis on variety and autonomy when they first enter the workforce and from an increasing emphasis on these work goals as they move up the hierarchy. We therefore recommend that students be provided with more information about the effects of job and organization design trends on the availability and importance of these key work goals. Hopefully this will lead to some functional adjustment of the students' priorities. Research and theory on modeling and goal adjustment suggest effectiveness is likely to be increased if the information provided to students also contrasts their work goals with those of managers and if self-assessment is encouraged in some manner.

Some functional adjustment of students' perceptions of the importance of job security and promotion opportunities may also be accomplished with information about their reduced availability and the low priority given to them by managers. The low priority given job security by managers may reflect not only modern organizational realities but also the managers' belief that their competencies provide them with considerable work if not organizational job security. If true, significantly reducing student perceptions of the importance of job security is likely to require strengthening student confidence and increasing their recognition that competencies can provide a different form of work security.

\section{Managerial Implications}

If the results of this study can be generalized to other business student populations, managers need to be aware of the contrasts between their priorities and those of graduating business students. And they need to think through the implications of these differences for motivation, job design, and career guidance when these students come to work for them. Managers cannot count upon educators to convey the importance of variety, autonomy, and matching abilities with job requirements to these students. Even if they could, that information might not have the desired effect when presented by educators. New graduates are likely to identify strongly with their managers and be receptive to their advice and counsel. This identification and receptiveness may also make managers a preferred change agent in preparing new business school graduates for the lower job security and fewer promotional opportunities available in today's organizations.

\section{Compatible Work Goal Priorities}

Learning skills and opportunities are extremely important in the dynamic workplace that characterizes modern organizations. Individuals need these skills and opportunities to keep up with changing work requirements and ensure their marketability in the workplace. Since upper division students rated learning opportunities significantly higher than their lower-division counterparts, functional adjustment appears to have occurred as expected during progression through the business curriculum. Functional adjustment also appears to have occurred in the students' changing views on the importance of interpersonal relations. The higher importance ratings by upper-division students suggest a better workplace fit in modern organizations where effective teamwork is often essential. The students' emphasis on good pay as a work goal is likely to be functional for their motivation in modern organizations as an increasing number tie significant rewards to performance (Avila, 2007). Pay continues to be an often-used reward for managers not only in periods of economic growth but also in stagnant and even recessionary times (Armour, 2002).

\section{Managerial Implications}

If the priorities found in this study can be generalized to other business student populations, managers will find new graduates highly motivated and satisfied by higher pay, learning opportunities, and interesting work. They will also find that new graduates understand the importance of team work and are anxious to develop good interpersonal relationships that will facilitate it. Hopefully the manager will have the pay and job design latitude to take advantage of these work goals. 


\section{Future Research Questions}

The current research suggests that graduating business students may have work adjustment problems due to a mismatch between their work goal priorities and the rewards and requirements of today's organizations. Whether these results hold at other institutions is a question for future research. So, too, are questions concerning the effects of curriculum changes and out-of-class educational opportunities. Integrating a work-adjustment learning module into the coursework may mitigate potential work adjustment problems, but research has yet to be done on the effects of such a module. Internships, networking, and mentoring are three out-of-class opportunities which may functionally impact work goal priorities. Internships are frequently touted as an excellent way for students to learn first hand about the world of work, and networking and mentoring offer vicarious learning and modeling opportunities that may affect work adjustment. Research is needed to examine the effectiveness of these factors and others in producing functional changes in student work goal priorities.

The current study only considered undergraduate students' work goals, and made no attempt to examine the possible effects of cultural variables. But education and culture are likely to play important roles in developing work goal preferences, and the trend toward globalization has resulted in many foreign-born employees in the U.S. workplace and in its institutions of higher education. Future research using graduate students and international students appears warranted.

\section{REFERENCES}

1. Abdolmohammadi, M. J. \& Reeves M. F. 2000. Effects of education and intervention on business students' ethical cognition: A cross sectional and longitudinal study. Teaching Business Ethics, 4, 269-284.

2. Ardichvili, A. 2005. The meaning of working and professional development needs of employees in a postcommunist country. International Journal of Cross Cultural Management: CCM, 5, 105-119.

3. $\quad$ Armour, S. 2002. Companies stretch time between pay raises. U.S.A. Today, August 30: 1B.

4. $\quad$ Aronson, E. 1995. The Social Animal. $7^{\text {th }}$ Edition. New York: W.H. Freeman and Company.

5. De Avila, J. 2007. More firms base raises on performance. Wall Street Journal, 250, 38, D5.

6. $\quad$ Bandura, A. 1977. Social Learning Theory. Englewood Cliffs, NJ: Prentice Hall.

7. Brief, A.P. 1991. MOW revisited: a brief commentary. European Work and Organizational Psychology, 1, 176-182.

8. Carrolll, A.B. and Buchholtz, A.K. 2006. Business and Society: Ethics and Stakeholder Management (6 ${ }^{\text {th }}$ Edition) Southwestern.

9. Chan, C.A. and Pearson, C.A.L. 2002. Comparison of managerial work goals among Bruneian, Malaysian and Singaporean managers. The Journal of Management Development, 21, 545-556.

10. Clark, M. M. 2005. Employees, HR differ on satisfaction factors, HR Magazine, August, 32, 40.

11. Cohen, J. 1969. Statistical Power Analysis for the Behavioral Sciences. New York: Academic Press.

12. Corney, W.J. and Richards, C.H. 2001. Work goal differences: post communist versus capitalistic economics. International Journal of Management, 18, 294-300.

13. Corney. W.J. and Richards, C.H. 2005. A comparative analysis of the desirability of work characteristics: Chile versus the United States. International Journal of Management, 22, 159-165.

14. Dawis, R.V. and Lofquist, L.H. 1984. A Psychological Theory of Work Adjustment: An Individual Differences Model and Its Applications. Minneapolis: University of Minnesota Press.

15. Dodd, N.G. and Ganster, D.C. 1966. The interactive effects of autonomy, variety and feedback on attitudes and performance. Journal of Occupational Behavior, 17, 329-347.

16. Dunegan, K.J., Uhl-Bien, M., and Duchon, D. 2002. LMX and subordinate performance: the moderating effects of task characteristics. Journal of Business \& Psychology, 17, 275-285.

17. Edwards, J.R. 1991. Person-job fit: a conceptual integration, literature review, and methodological critique. International Review of Industrial and Organizational Psychology, 6, 283-357.

18. Hackman R. and Oldham, G. 1980. Work Redesign. Reading, MA: Addison Wesley.

19. Hammer, M. and Champy, J. 1993. Reengineering the Corporation. New York: Harper Business.

20. Harpaz, I. 1990. The importance of work goals: an international perspective. Journal of International Business Studies, 21, 75-93. 
21. Harpaz, I. and Fu, X. 2002. The structure of the meaning of work: a relative stability amidst change. Human Relations, 55, 639-667.

22. Harris, C., Daniels, K., and Briner, R.B. 2003. A daily diary study of goals and affective well-being at work. Journal of Occupational and Organizational Psychology, 76, 401-410.

23. Hershenson, D. B. 1996. Work adjustment: A neglected area in career counseling. Journal of Counseling and Development, 74, 442-449.

24. Kim, D., Markham, F.S., and Cangelosi, J.D. 2002. Why students pursue the business degree: a comparison of business students across universities. Journal of Education for Business, 77, 28-32.

25. Leach, D.J., Wall, T.D., and Jackson, P.R. 2003. The effect of empowerment on job knowledge: An empirical test involving operators of complex technology. Journal of Occupational and Organizational Psychology, 76, 27-52.

26. Locke, E.A. 1976. The nature and causes of job satisfaction. In M.D. Dunnette (Ed.), Handbook of Industrial and Organizational Psychology. 1297-1349. Chicago: Rand McNally.

27. Maier, G.W. and Brunstein, J.C. 2001. The role of personal work goals in newcomers' job satisfaction and organizational commitment: a longitudinal analysis. Journal of Applied Psychology, 86, 1034-1042.

28. MOW International Research Team. 1987. The Meaning of Work. London: Academic Press.

29. Pearson, C.A.L. and Chatterjee, J.R. 1999. Changing work values of senior Indian managers: an empirical study. International Journal of Management, 16, 139-146.

30. Peterson, M.F. and Ruiz-Quintanilla, S.A. 2003. Cultural socialization as a source of intrinsic work motivation. Group and Organizational Management, 28, 188-216.

31. Rest, J. 1986. Moral Development: Advances in Theory and Research. New York: Praeger Publishers.

32. Rest, J. 1994. "Background: Theory and research" in J.R. Rest and D. Narvaez (Eds), Moral Development in the Professions. Hillsdale, NJ: Erlbaum.

33. Schalaefli, A., Rest, J. R. and Thoma, S.J. 1985. Does moral education improve moral judgment? A metaanalysis of intervention studies using the Defining Issues Test. Review of Educational Research, 55, 319352.

34. Robertson, L. 1990. Prediction of job satisfaction from characteristics of personal work goals. Journal of Organizational Behavior, 11, 29-41.

35. Stewart, G.L., Manz, C.C., and Sims, H.P. 1999. Team Work and Group Dynamics. New York: John Wiley and Sons.

36. Trist, E.L. 1981. The Evolution of Socio-Technical Systems. Toronto, ON: Quality of Working Life Center.

37. Weiner, Y. and Klein, K.L. 1978. The relationship between vocational interests and job satisfaction: Reconciliation of divergent results. Journal of Vocational Behavior, 13, 298-304.

38. Welsch, H. 2005. Adaptation of tastes to constraints. Theory and Decision, 57, 379-395. 